\title{
ENVIRONMENTAL FORENSICS: WHERE TECHNIQUES AND TECHNOLOGIES ENFORCE SAFETY AND SECURITY PROGRAMS
}

\author{
M. LEGA $^{1} \&$ R. TETA ${ }^{2}$ \\ ${ }^{1}$ University of Naples Parthenope, Department of Engineering, Italy. \\ ${ }^{2}$ University of Naples Federico II, Department of Pharmacy, Italy.
}

\begin{abstract}
Safety and security engineering involve several and complex multidisciplinary activities aimed to preserve people and the environment from hazards and risks. These concepts that were born as "umbrella" terms for the laws, rules; process design is generally applied only for workplaces or related to the employees; indeed, the scenario of related applications is only limited by the typical needs of the specific context. Recently, new methods and applications for detecting, evaluating, and tracking signs of environmental contamination are validating the effectiveness of safety and security engineering tools also in the environmental field. As in a workplace an engineer is called to analyze a complex scenario (e.g. to evaluate a risk, to assess a real danger and, therefore, look for causes to define the dynamics and find a solution), in the same way the environmental forensic scientist has to examine scenarios and actors to define the relationships to reveal source, path and target; in both the same techniques and technologies used in the analyses play a key role. This paper introduces a multidisciplinary strategy that bridges different approaches incorporating remote/proximal sensing applications where techniques and technologies enforce safety and security programs. A part of Campania coast, close to Salerno city in southwestern Italy, was chosen as a test bed of our strategy. All the activities were performed supporting the environmental investigations directed by Salerno Prosecutor Office and also cooperating with Italian police and several Government bodies. This paper provides an example where law enforcement and university research teams collaborate to develop enhanced environmental protection methods.

Keywords: aerial infrared thermography, bioindication, eco crimes, environmental forensics, environmental violations, GIS, law enforcement, public health, remote sensing.
\end{abstract}

\section{INTRODUCTION}

Environmental forensic science applies scientific methods to the investigation of environmental crimes and contamination events; therefore, the environmental forensic scientist has to examine scenarios and actors to define the relationships to reveal source, path and target, thus helping to identify the culprit of a specific environmental damage. This paper introduces a multidisciplinary strategy that bridges different approaches incorporating remote/proximal sensing applications where techniques and technologies enforce safety and security programs. A part of Campania coast, close to Salerno city in southwestern Italy, was chosen as test a bed of our strategy. All the activities were performed supporting the environmental investigations directed by the Salerno Prosecutor Office and also cooperating with Italian police and several Government bodies. Since this paper point out the novelty of the followed approach and of the advanced techniques and technologies used in a real investigation process, also the description in the paper will follow all the main steps of a real case solved by the Salerno Prosecutor Office with the contribution of one of the author as technical consultant. In detail, the specific case was related to ascertain the presence of unauthorized discharges and/or pollutants in water bodies of Salerno coast, and/or other critical environmental issues related to waterways and to assess the anthropic impact on the water streams to identify possible adverse effects on human health and on the ecosystem. 
The investigation methodology has been based on the criteria identified in the causal connection between the offender and offense and the analysis of the operating scenario; both analyses were carried out keeping in mind the uniqueness and magnitude of the investigated area.

The offender is the person responsible of the pollutant source; therefore, to define them it is useful to classify the pollutants sources with the following criteria: 1) discharges origin; 2) continuity of discharges; 3 ) permissibility of discharges.

According to the first criterion, discharges origin, the discharges are defined as urban or industrial and, moreover, spot or distributed.

Regarding the second criterion, the continuity of discharges, there are only two types: continuous and discontinuous or intermittent.

Finally, regarding the third criterion, the permissibility of discharges, the classes are two distinct that require also significantly different logistic approaches: control and verification measures to the authorized releases; search, detection and location of illegal discharges.

According to the definition of environmental crime, crime is any breach of the rules on discharges, or discharges made without authorization and/or breach of the limits of the quality of discharges of any kind delivered in a river basin. The gravity of the offense is related to the feasibility of remediation of water bodies.

In our case it seemed appropriate to broaden the assumptions for the definition of the investigation methodology also to the damage or risk of damage caused by spilled pollutants on possible targets as natural resources (rivers, lands and sea), human activities (e.g. agriculture, livestock farming, fishing, recreational activities), human health.

When law enforcement investigates environmental criticalities linked to discharges, all the above considerations represent a guideline that has to be taken into account to successfully prosecute the responsible parties. Investigators must be able to produce a validated dataset using recognized scientific methods, such as random sampling. Remote and proximal sensing data integrated with data collected on the site can support the investigation process reducing the examined area, revealing the causal connection between the pollution source and the environmental damage. This study employed traditional law enforcement evidentiary methods, validating the combined use of remote, proximal sensing and in situ data with a strong contribution of IT (Information Technology) tools.

\section{MATERIALS AND METHODS}

In this study, we used a hierarchical monitoring approach ranging from remote/proximal sensing to analytical in situ methods. All the used tools, facilities and the cooperation between police, government bodies and University teams create a virtual unique "infrastructure" (Fig. 1).

In the environmental field the investigation often begins with the evidence of the damage and not of the illegal polluting act; indeed, the consequences of pollution appear far away in time and space from the polluting act. The presented infrastructure reveals the conceptual flow of the performed investigations where a top-down approach permitted at first to reduce the investigated area identifying criticalities, then defining actors and the specific dynamics of the typical environmental pollution model "source-path-target".

In this study the satellite remote sensing data were obtained from the Landsat 8 operational land imager sensor (OLI) to create the Normalized Difference Vegetation Index (NDVI) [1] images for the scene. We analyzed the range of NDVI values only for the data related to the water surface, using data extraction techniques based on the Normalized Difference Water Index (NDWI) [2]. 


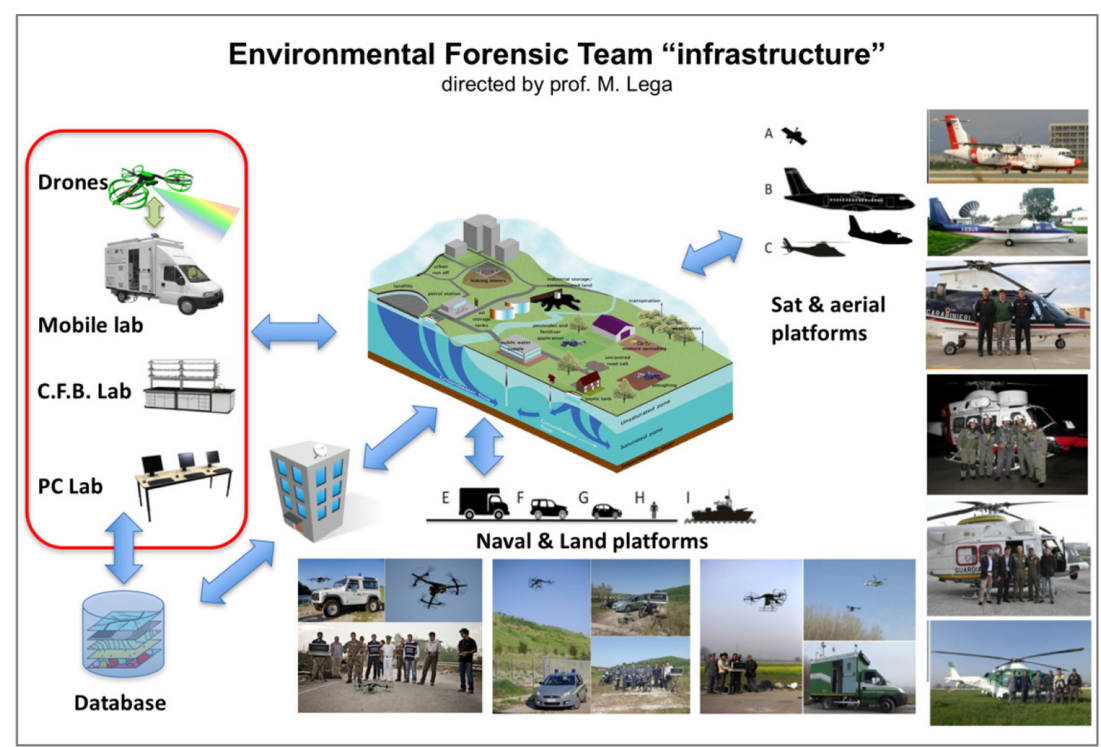

Figure 1: The virtual unique "infrastructure" combining tools, platforms, facilities and the cooperation between police, government bodies and university teams.

The remote/proximal sensing data obtained using Landsat 8 were validated in several environmental monitoring missions with complex scenarios as reported in previous works; these include: a combined use of remote/proximal sensing applications with analytical/biotechnological analyses for the early detection of cyanobacterial blooms for water quality assessment [3, 4].

Remote sensing studies typically use only satellite data, but in our approach we have combined the data acquired by several aerial platforms (sat, aircraft, rotorcraft and UAV/DRONE) to permit enhanced resolution and flexibility on various spatial and temporal scales. During the past years our team have already partially tested in several real missions in Italy the use of this range of aerial platforms and advanced sensors to detect the illegal activities $[5,6]$, but this is the first time that we can appreciate the "power" of the full chain of platform finalized to hierarchic monitoring.

In addition, remote sensing data can be strategically combined with other data layers, including: fusion of optical data with synthetic aperture radar data to detect environmental hazards [7, 8], use of thermal imagery to monitor landfills [9], surface waters contamination $[10]$ and to detect illegal dumping $[11,12]$ and to identify other illegal activities $[13,14]$. Moreover, using the data acquired during the missions with geographic information systems (GIS) it is possible to anticipate environmental violations $[15,16]$ and to monitor the vulnerability of cultural sites [17].

In this study, to perform remote/proximal sensing activities, we used two different types of aircraft: ATR 42 MP and a Rockwell Aero Commander 685.

The use of the first aircraft was derived from the cooperation with the Italian Coast Guard and the second one has been made available by the Regional Agency for Environmental Protection in Campania thanks to an agreement with the company Avioriprese.

The ATR 42 MP carried onboard the Sensytech 1268 ATM-E multispectral scanning sensor that can detect the surface reflected energy turning it into 12 digital images that cover the range of visible, near and middle IR bands. 
The Rockwell Aero Commander 685 was equipped with a four bands camera (Intergraph DMC) placed on an inertial platform (Applanix POS/AV 510-DG) and linked to a GPS system.

Two lightweight, twin-engine, eight-seat multi-purpose helicopters (Augusta Westland $139 \mathrm{~N}$ ) were used in the missions thanks to a cooperation with the Italian police bodies (Carabinieri and Italian Financial Police). The rotorcrafts carried onboard the standard multisensor optical payload specialized for search and rescue missions and, moreover, two IR cameras with radiometric output (FLIR SC660, Flir T620).

We are currently investigating the possibility to identify, with the combined use of these tools and analyses on site, different symptoms of eutrophic conditions due to the anthropogenic pressure on waters which receive diverse pollutants (wastewater or contaminated waters), such as the presence of bioindicators such as microorganisms (cyanobacteria) [18], and molecules (toxins) [19, 20].

\section{RESULTS}

As we highlight in previous experiences in Campania coast (south Italy), the coastal regions contaminated by polluted river water leaving inland river basins can be difficult to monitor due to their size and remoteness, so a complex multilevel visual and digital processing was carried out to detect and track signs of contaminations and other "anomalies".

It is necessary to point out that the scenario for the assessment of the state of pollution of water bodies under investigation could not be limited only to river courses, but had to be extended to the whole basin.

The first step of the approach was the acquisition and the analysis of satellite data that reveal the potential alterations of the water quality and shows as the plumes generated in correspondence specific delta rivers are pulled/pushed from the sea currents to the whole area gulf of Salerno.

In particular, as shown in Fig. 2, the bigger sources are the Picentino (R1), Tusciano (R2) and Sele (R3) rivers and the releasing of these water courses arrives to impact in the north area of the gulf of Salerno as also the Amalfi coast.

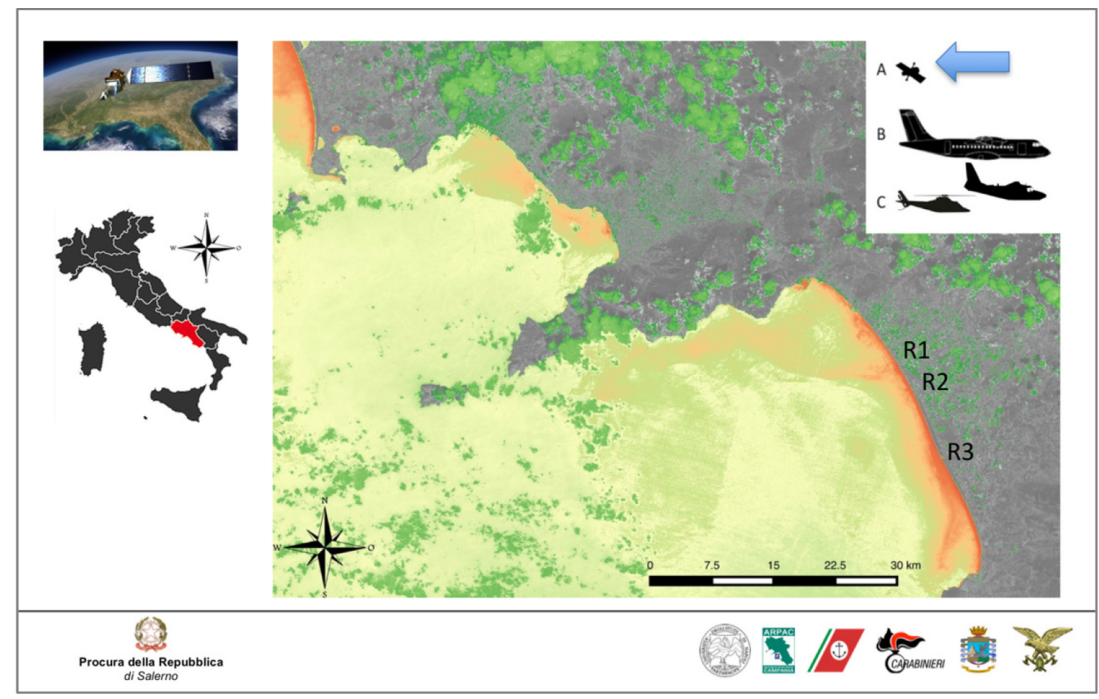

Figure 2: Landsat 8 NDVI rendering reveals plumes near study sites and the impact on coastal areas. 


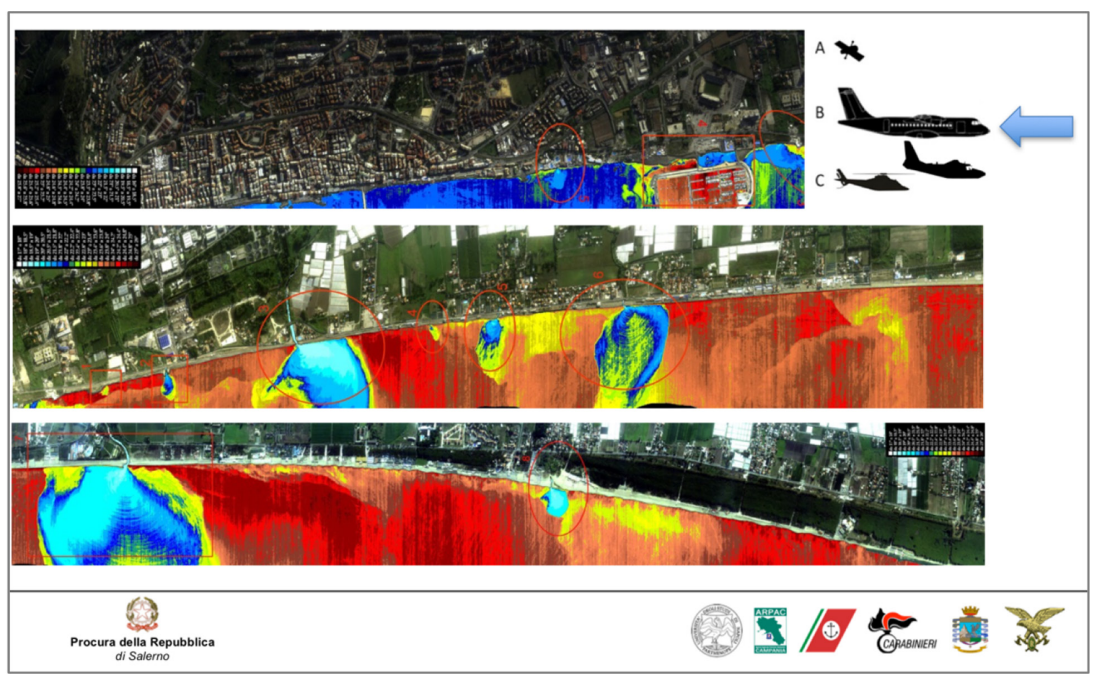

Figure 3: The rendering of thermal band, overlapped with RGB signal, acquired by multispectral sensor carried on board the ATR $42 \mathrm{MP}$.

The second step of the approach was the acquisition and the analysis of multispectral data captured by the sensor carried on board the ATR 42 MP.

In particular, the thermal band, overlapped with RGB signal (Fig. 3), highlights with an incredibly high resolution the hot spots related to delta rivers and, sometime, also, the presence of big pipelines related to illegal water discharges.

This step permitted to identify a specific area of the coast that represents a first source of pollution for the sea.

Obviously, at this level of investigation more studies are needed to identify the single plume sources along each river body.

Because the geometric resolution of a multispectral sensor carried onboard the ATR42 MP was poor, we introduced a fourth step based on the use of the other aircraft available: Rockwell Aero Commander 685. This aircraft thanks to specific sensor carried onboard and the flight plan defined with specific altitude have guaranteed a resolution of 7-8 cm/pixel.

In Fig. 4 we can notice the high resolution of data acquired by Intergraph DMC onboard the Rockwell Aero Commander 685; indeed, it is possible to identify details related to cars and motorcycles present in the scene.

Moreover, since the Intergraph DMC is a four bands (R, G, B and NIR) sensor, it is possible to use this data also to produce a high definition NDVI indexing.

In the fifth step we entered the data acquired during missions in GIS, and we have planned several helicopter flight plans over specific areas.

The sixth step was dedicated to perform missions using the rotorcrafts (Augusta Westland $139 \mathrm{~N}$ ). During these missions, using IR cameras with radiometric output, we identified "anomalies" related to spills and other tracks/evidences, among them, but we have not considered those with the permissibility of discharges; indeed, in real time it was possible to cross-correlate the data acquired with those of a specific database designed to support our missions (Fig. 5). 


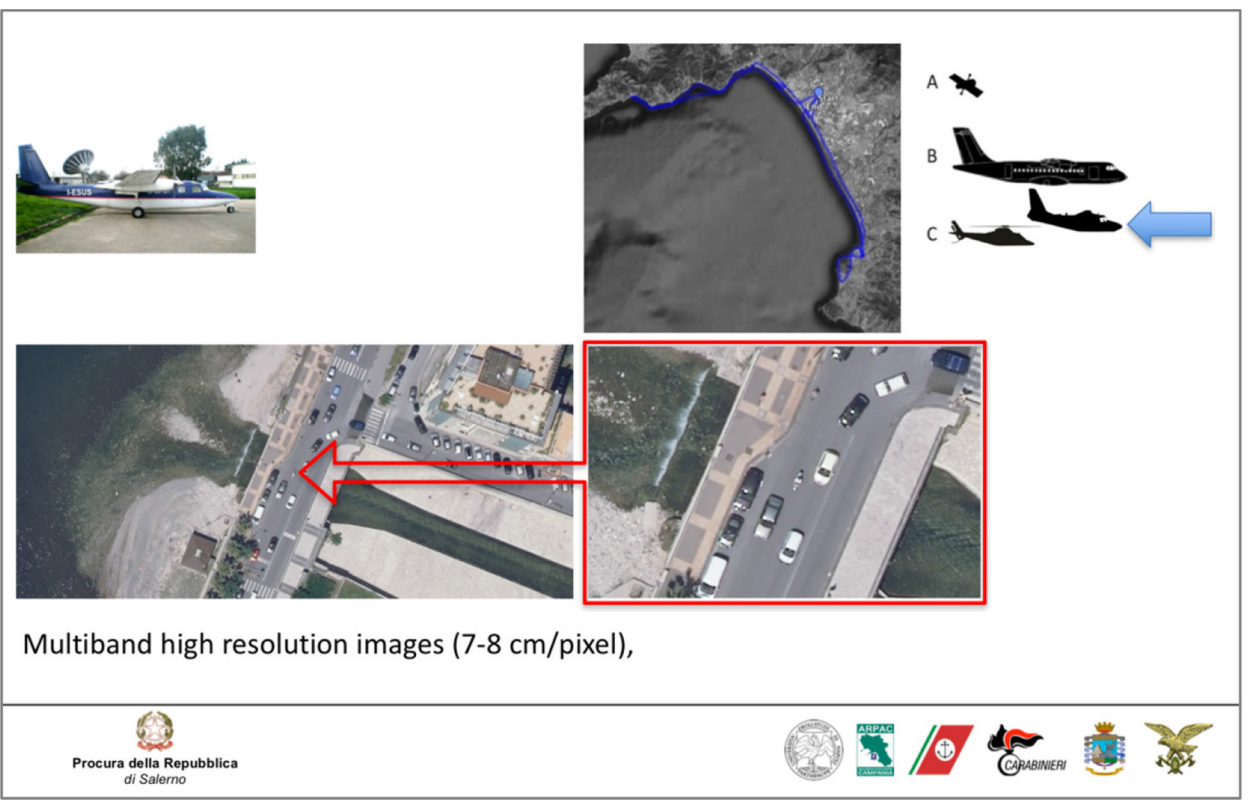

Figure 4: RGB data acquired by Intergraph DMC onboard the Rockwell Aero Commander 685.

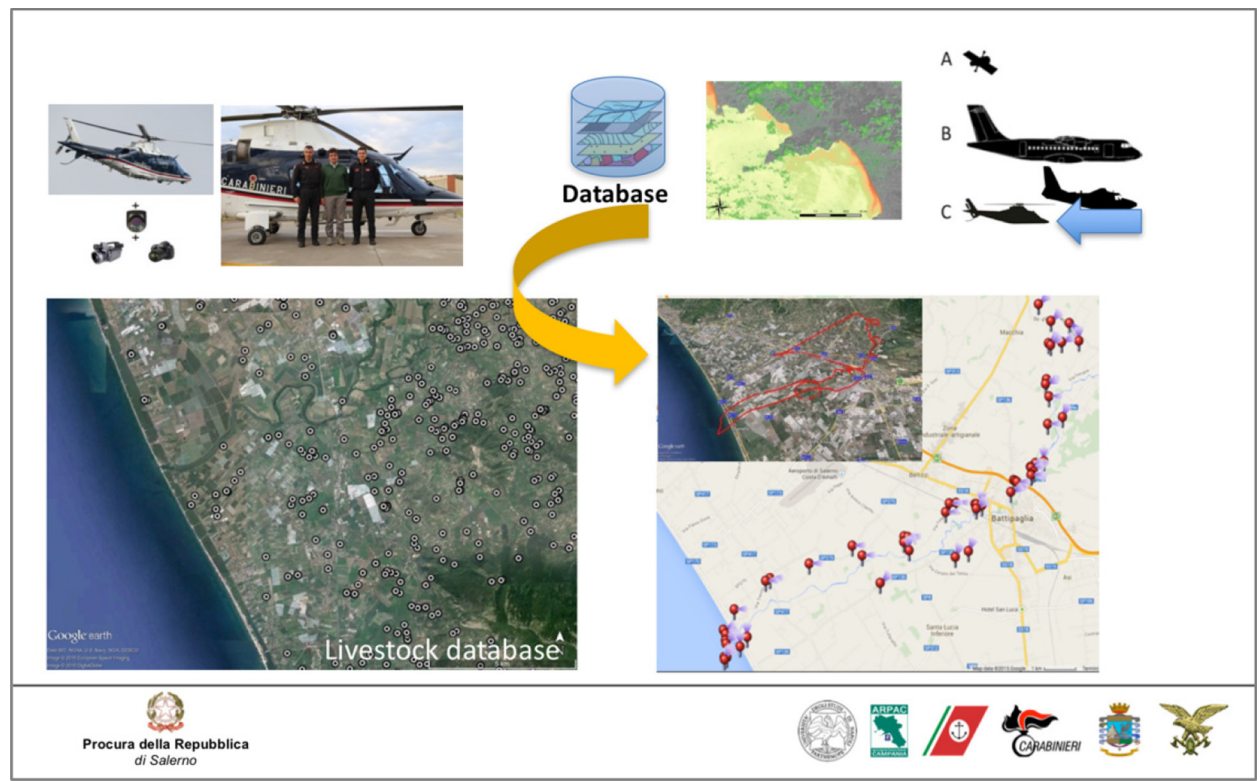

Figure 5: Example of mission performed using the Carabinieri rotorcraft (Augusta Westland $139 \mathrm{~N}$ ) and cross-correlation with the information provided in the database. 


\section{DISCUSSION}

Several illegal activities were revealed during the investigation thanks to the approach here proposed.

Respecting the limits imposed by the Prosecutor Office it is not possible to introduce here all details of the cases solved, but we can present some examples that show some typical illegal acts as discovered and how this is revealed by our technique and technologies.

A first example is related to "bad" practices operated by livestock farms that try to avoid the costs and criticalities of animal waste management, introducing a bypass system that permits the direct discharge in a close river/water stream.

We located the specific farm to examine with the first four steps of the proposed approach and the last step, thanks to a thermal view acquired from a rotocraft with onboard a IR thermal camera, reveals the "hot" flow of waste directed to the river (Fig. 6).

The second example refers to another illegal behavior related to buffalo waste management; in this case the livestock farm had not a permanent connection with the river but an intermittent drain consisting of a rubber pipeline used to discharge the waste from the close reservoir as needed. Although this operation was done occasionally and therefore it could not be caught in the act, during the investigations, it was possible to notice traces on the grass (at first detected by radiometric data, then confirmed by RGB/visible pictures) due to continuous trampling of the pump truck wheels in the path between the reservoir and the river, that aroused suspicions (Fig. 7).

Finally, aerial radiometric infrared pictures of all the river plumes present in the investigated area were captured (Fig. 8) and this data could be analyzed by a combination of remote sensing and river basin modelling to estimate their spatial, temporal, and water quality characteristics already made in previous work [21].

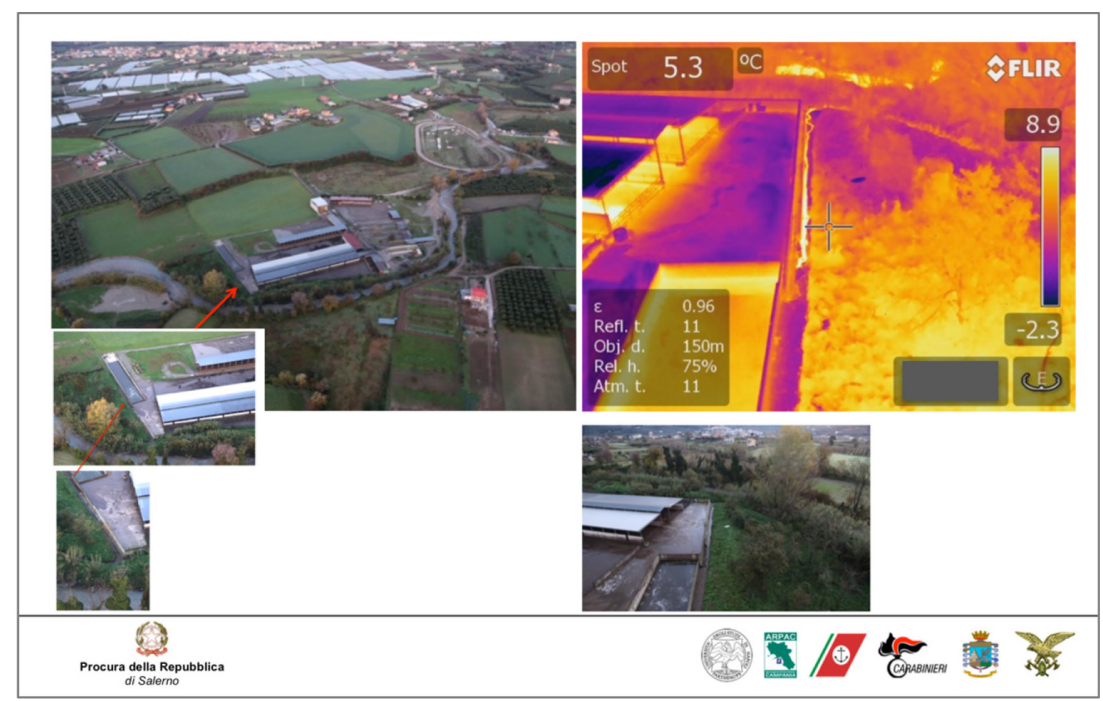

Figure 6: Example of illegal activity operated by a livestock farm (buffalo farm): standard aerial view (on the left side), thermal view (on the right side) that reveal the "hot" flow of dejection directed to the river. 


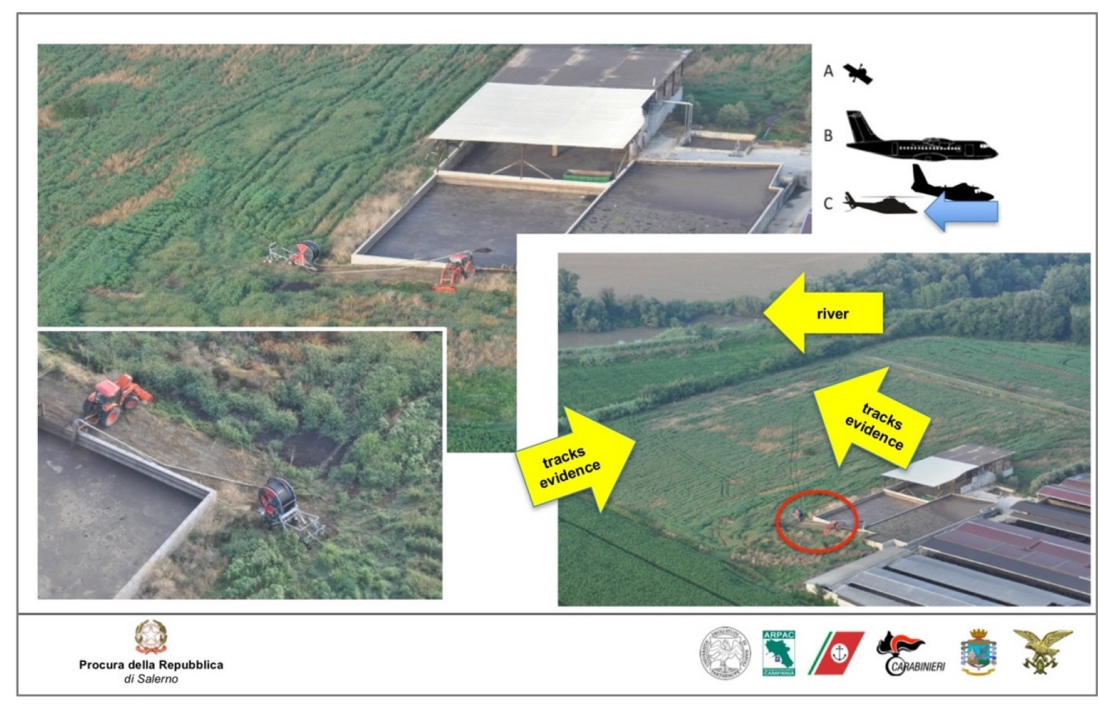

Figure 7: Example of illegal activity operated by a livestock farm (buffalo farm): notice traces on the grass (at first detected by radiometric data, then confirmed by RGB/visible pictures) due to continuous trampling of the pump truck wheels in the path between the reservoir and the river.

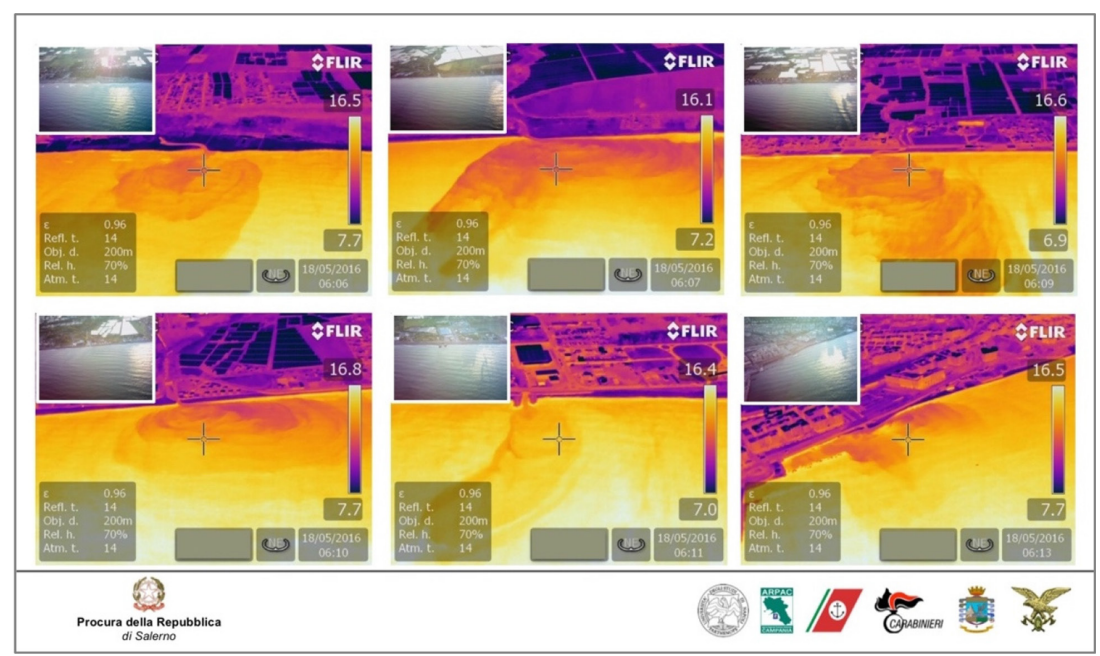

Figure 8: Example of radiometric infrared data of several river plumes present in the investigated area.

\section{CONCLUSION}

The innovative approach here proposed, based on a complex infrastructure combining resources, procedures and tools, has demonstrated its effectiveness in field trials during a real investigation process requested by the Salerno Prosecutor Office and no examples of a similar complex system have been reported so far. The acquired data represent also an invaluable 
background because they can be further processed for the safety and security and law enforcement, in the aim of a better land management as for prevention in the latter case.

\section{ACKNOWLEDGEMENT}

This work has been partially funded by Università degli Studi di Napoli Parthenope under

"Bando di sostegno alla ricerca individuale per il triennio 2015-2017"

This work has been partially funded by Università degli Studi di Napoli Federico II under the STAR project SeaLEADS.

We wish to acknowledge the Italian Public Prosecutor's Office in Salerno directed by dott. Corrado Lembo.

The authors are grateful for the support from Italian polices (Carabinieri, Guardia Costiera, Guardia di Finanza, Corpo Forestale dello Stato) and the Regional Environmental Protection Agency in Campania (ARPAC).

\section{REFERENCES}

[1] Rouse, J.W., Haas, R.H., Schell, J.A. \& Deering D.W., Monitoring vegetation systems in the great plains with ERTS. Third ERTS Symposium, NASA SP-351 I, pp. 309-317, 1973.

[2] Gao, B-C, NDWI a normalized difference water index for remote sensing of vegetation liquid water from space. Remote Sensing of Environment, 58, pp. 257-266, 1996. https://doi.org/10.1016/S0034-4257(96)00067-3

[3] Teta, R., Della Sala, G., Mangoni, A., Lega, M. \& Costantino, V., Tracing cyanobacterial blooms to assess the impact of wastewaters discharges on coastal areas and lakes. International Journal of Sustainable Development and Planning, 11(5), pp. 804-811, 2016. https://doi.org/10.2495/SDP-V11-N5-804-811

[4] Teta, R., Romano, V., Della Sala, G., De Sterlich, C., Picchio, S., Mangoni, A., Di Tullio, G., Costantino, V. \& Lega, M., Cyanobacteria as indicators of water quality in Campania coasts, Italy: a monitoring strategy combining remote/proximal sensing and in situ data. Environmental Research Letters, in press, 2016.

[5] Lega, M., Ceglie, D., Persechino, G., Ferrara, C. \& Napoli, R.M.A., Illegal dumping investigation: a new challenge for forensic environmental engineering. WIT Transactions on Ecology and the Environment, 163, pp. 3-11, 2012. https://doi.org/10.2495/WM120011

[6] Lega, M., Kosmatka, J., Ferrara, C., Russo, F., Napoli, R.M.A. \& Persechino, G., Using advanced aerial platforms and infrared thermography to track environmental contamination. Environmental Forensics, 13(4), pp. 332-338, 2012.

https://doi.org/10.1080/15275922.2012.729002

[7] Errico, A., Angelino, C.V., Cicala, L., Persechino, G., Ferrara, C., Lega, M., Vallario, A., Parente, C., Masi, G., Gaetano, R., Scarpa, G., Amitrano, D., Ruello, G., Verdoliva, L. \& Poggi, G., Detection of environmental hazards through the feature-based fusion of optical and SAR data: a case study in southern Italy. International Journal of Remote Sensing, 36:13, pp. 3345-3367, 2015. https://doi.org/10.1080/01431161.2015.1054960

[8] Errico, A., Angelino, C.V., Cicala, L., Podobinski, D.P., Persechino, G., Ferrara, C., Lega, M., Vallario, A., Parente, C., Masi, G., Gaetano, R., Scarpa, G., Amitrano, D., 
Ruello, G., Verdoliva, L. \& Poggi, G., SAR/multispectral image fusion for the detection of environmental hazards with a GIS. Proceedings of SPIE - The International Society for Optical Engineering, 9245, 924503, 2014.

[9] Lega, M. \& Napoli, R.M.A., A new approach to solid waste landfills aerial monitoring. WIT Transactions on Ecology and the Environment, 109, pp. 193-199, 2008. https://doi.org/10.2495/WM080211

[10] Lega, M. \& Napoli, R.M.A., Aerial infrared thermography in the surface waters contamination monitoring. Desalination and Water Treatment, 23(1-3), pp. 141-151, 2010. https://doi.org/10.5004/dwt.2010.1988

[11] Persechino, G., Schiano, P., Lega, M., Napoli, R.M.A., Ferrara, C. \& Kosmatka, J., Aerospace-based support systems and interoperability: The solution to fight illegal dumping. WIT Transactions on Ecology and the Environment, 140, pp. 203-214, 2010. https://doi.org/10.2495/WM100191

[12] Persechino, G., Lega, M., Romano, G., Gargiulo, F. \& Cicala, L., IDES project: an advanced tool to investigate illegal dumping. WIT Transactions on Ecology and the Environment, 173, pp. 603-614, 2013.

https://doi.org/10.2495/SDP130501

[13] Lega, M., Ferrara, C., Persechino, G. \& Bishop, P., Remote sensing in environmental police investigations: aerial platforms and an innovative application of thermography to detect several illegal activities. Environmental Monitoring and Assessment, 186(12), pp. 8291-830, 2014. https://doi.org/10.1007/s10661-014-4003-3

[14] Gargiulo, F., Angelino, C.V., Cicala, L., Persechino, G. \& Lega, M., Remote sensing in the fight against environmental crimes: The case study of the cattle-breeding facilities in southern Italy. International Journal of Sustainable Development and Planning, 11(5), pp. 663-671, 2016. https://doi.org/10.2495/SDP-V11-N5-663-671

[15] Lega, M. \& Persechino, G., GIS and infrared aerial view: Advanced tools for the early detection of environmental violations. WIT Transactions on Ecology and the Environment, 180, pp. 225-235, 2014. https://doi.org/10.2495/WM140191

[16] Gargiulo, F., Persechino, G., Lega, M. \& Errico, A., IDES project: A new effective tool for safety and security in the environment. Lecture Notes in Computer Science (including subseries Lecture Notes in Artificial Intelligence and Lecture Notes in Bioinformatics), 8286 LNCS (PART 2), pp. 201-208, 2013.

[17] Lega, M., D’Antonio, L. \& Napoli, R.M.A., Cultural heritage and waste heritage: advanced techniques to preserve cultural heritage, exploring just in time the ruins produced by disasters and natural calamities. WIT Transactions on Ecology and the Environment, 140, pp. 123-134, 2010.

https://doi.org/10.2495/WM100121

[18] Teta, R., Della Sala, G., Glukhov, E., Gerwick, L., Gerwick, W.H., Mangoni, A. \& Costantino, V., Combined LC-MS/MS and molecular networking approach reveals new cyanotoxins from the 2014 cyanobacterial bloom in Green Lake, Seattle. Environmenal Science and Technology, 49(24), pp. 14301-14310, 2015. https://doi.org/10.1021/acs.est.5b04415

[19] Teta, R., Irollo, E., Della Sala, G., Pirozzi, G., Mangoni, A. \& Costantino, V., Smenamides A and B, chlorinated peptide/polyketide hybrids containing a dolapyr- 
rolidinone unit from the Caribbean sponge Smenospongia aurea, Evaluation of their role as leads in antitumor drug research. Marine Drugs, 11(11), pp. 4451-4463, 2013. https://doi.org/10.3390/md11114451

[20] Esposito, G., Teta, R., Miceli, R., Ceccarelli, L., Della Sala, G., Camerlingo, R., Irollo, E., Mangoni, A., Pirozzi, G. \& Costantino, V., Isolation and assessment of the in vitro anti-tumor activity of smenothiazole A and B, chlorinated thiazole-containing peptide/ polyketides from the Caribbean sponge, Smenospongia aurea. Marine Drugs, 13, pp. 444-459, 2015. https://doi.org/10.3390/md13010444

[21] Lega, M. \& Endreny, T., Quantifying the environmental impact of pollutant plumes from coastal rivers with remote sensing and river basin modelling. International Journal of Sustainable Development and Planning, 11(5), pp. 651-662, 2016.

https://doi.org/10.2495/SDP-V11-N5-651-662 